\title{
Expansão da pós-graduação nas IFES em MS: uma análise das condições materiais e simbólicas
}

\author{
Expansion of graduation education in IFES in MS: \\ an analysis of material and symbolic conditions
}

\author{
Ana Maria Silva Magalhães ${ }^{1}$ \\ Giselle Cristina Martins Real ${ }^{2}$
}

Resumo: Busca-se analisar a expansão da pós-graduação stricto sensu nas universidades federais sul-matogrossenses no contexto das políticas expansionistas implementadas no conjunto das IFES brasileiras a partir de 2003. As análises foram realizadas à luz da literatura da área, documentos e estatísticas oficiais, com base nas noções de campo, capital simbólico e de habitus de Bourdieu. Como resultados, observou-se que a expansão da pós-graduação se deu pela combinação de políticas governamentais indutoras - com certa recuperação das IFES, sobretudo em termos de quantitativo docente - de ações de indução dos gestores universitários e da própria ação docente, particularmente pela manutenção do habitus da pós-graduação. Esse movimento engendrou a expansão da pós-graduação nas universidades federais do MS, embora os agentes institucionais ainda precisem consolidar a expansão qualitativa, uma vez que possuem circulação restrita no campo da pós-graduação nacional/internacional. Em termos de espaços de poder, verifica-se a baixa participação desses agentes nas instâncias decisórias da CAPES. Em termos de capital de prestígio intelectual, há baixa participação em bancas de defesa de programas de pós-graduação de outras IES e baixa produção intelectual em periódicos dos estratos mais altos do Qualis. Essa situação, aprofundada pelo modelo avaliativo da CAPES, somente poderia ser minimizada com políticas mais efetivas de combate às assimetrias regionais em termos qualitativos, capazes de induzir a circulação no campo da pós-graduação em todas as unidades da federação, inclusive com maior inserção desses agentes nas instâncias decisórias dos órgãos gestores da pesquisa e da avaliação.

Palavras-chave: Políticas expansionistas. Pós-Graduação. Universidades federais. 
Abstract: The aim is to analyze the expansion of graduate courses in federal universities in the state of Mato Grosso do Sul in the context of the expansionist policies implemented in the universities since 2003. The analyzes were carried out in the light of the area's literature, documents and official statistics, which were based on Bourdieu's notions of countryside, symbolic capital and habitus. As a result, it was observed that the expansion of post-graduation was due to the combination of inductive government policies - with a certain recovery of the IFES, especially in terms of teaching quantity - of induction actions by university managers and of the teaching action itself, particularly due to the maintenance of postgraduate habitus. This movement led to the expansion of postgraduate studies at the federal universities of MS, although institutional agents still need to consolidate their qualitative expansion, since they have restricted circulation in the field of national / international graduate studies. In terms of instances of power, there is a low participation of these in decision-making bodies of CAPES - and in terms of capital of intellectual prestige, there is a low participation in defense boards of graduate programs from other universities and low intellectual production in journals of the highest strata of Qualis. This situation, deepened by the CAPES evaluation model, could only be minimized with more effective policies to combat regional asymmetries in qualitative terms capable of inducing the circulation of the graduate field in all units of the federation, including with a greater insertion of these agents in the decision-making bodies of the research and evaluation management bodies.

Keywords: Expansionist policies. Graduate education. Federal universities.

${ }^{1}$ Universidade Federal da Grande Dourados | Programa de Pós-graduação em Educação |
Dourados | MS | Brasil. Contato: anamagalhaes.dds@gmail.com.

ORCID: 0000-0001-6825-5825

${ }^{2}$ Universidade Federal da Grande Dourados | Programa de Pós-graduação em Educação | Dourados | MS | Brasil. Contato: gisellereal@ufgd.edu.br. ORCID:0000-0002-8855-4141

- Recebido em: 16 de dezembro de 2020

- Aprovado em: 12 de maio de 2021

DOI: http://dx.doi.org/10.1590/S1414-40772021000200010

Este é um artigo publicado em acesso aberto sob uma licença Creative Commons https://creativecommons.org/licenses/by-nc/4.0/ 


\section{Introdução}

O presente artigo possui como objetivo analisar a expansão da pós-graduação stricto sensu nas universidades federais em Mato Grosso do Sul (MS), tendo como contexto as políticas públicas para a expansão da educação superior implementadas pelo poder central no conjunto das universidades federais brasileiras a partir de 2003.

No período em tela, a significativa expansão da pós-graduação nas IFES em MS permitiu que a proporção do incremento de matrículas e de programas de pós-graduação permanecesse acima da média nacional, embora se trate de universidades localizadas fora dos grandes centros demográficos do país.

Diante disso, considerando o período abarcado, o lócus e os objetivos da pesquisa, elegeram-se os programas de Expansão das Universidades Federais (Expandir) ${ }^{1}$ e de Reestruturação e Expansão das Universidades Federais (Reuni) como políticas privilegiantes de análise.

Não obstante as variadas críticas (CAMPOS, 2017; MOURA; PASSOS, 2019), os programas Expandir e Reuni impactaram de forma significativa a expansão da educação superior em universidades federais durante sua vigência, inclusive no nível de pós-graduação (TREVISOL; BASTIANI; BRASIL, 2020; PAULA; ALMEIDA, 2020).

A Universidade Federal de Mato Grosso do Sul (UFMS) teve campi criados no contexto do programa Expandir. Também a Universidade Federal da Grande Dourados (UFGD) foi criada em 2005, com recursos conforme plano de expansão do referido programa.

UFMS e UFGD aderiram ao programa Reuni em 2007, por meio de um contrato com metas para implementação de 2008 até 2012, este previa expansão de cursos, vagas e matrículas. As universidades teriam como contrapartida o incremento nos recursos financeiros para infraestrutura, material de consumo e contratação de pessoal (BRASIL, 2007).

Em que pese as mudanças nas lógicas das políticas educacionais adotadas a partir de 2016 (AZEVEDO; CATANI, 2020; OLIVEIRA; AMARAL, 2020), pode-se afirmar que os efeitos iniciais dos programas Expandir e Reuni permaneceram, pelo menos, até 2018, considerando a criação de novas universidades, cursos e conclusão de turmas nesse contexto.

Para as análises, considerou-se a ação da Coordenação de Aperfeiçoamento de Pessoal de Nível Superior (CAPES), enquanto responsável pela avaliação e financiamento da Pós-

\footnotetext{
${ }^{1}$ Esse programa buscou a ampliação do parque universitário federal. Teve início em 2003, com metas previstas até 2014. Nesse sentido ver:

http://portal.mec.gov.br/expansao/images/APRESENTACAO_EXPANSAO_EDUCACAO_SUPERIOR14.pd $\mathrm{f}$ e http://portal.mec.gov.br/component/content/?view=202:noticias\&id=6592:sp-1567514816. Acesso em: 29 out. 2020
} 
Graduação no Brasil, bem como a ação do agente institucional, tanto em termos de gestão universitária, quanto em termos de atuação nos quadros docentes da pós-graduação.

Com isso, a seguinte problemática norteou a pesquisa: de que forma, programas como Reuni e Expandir, embora com foco na expansão da graduação, contribuíram para a expansão da pós-graduação nas universidades federais em MS? Quais as condições materiais e simbólicas que deram suporte/induziram a expansão da pós-graduação nessas instituições?

O artigo é dividido em três seções, além desta introdução e das considerações finais. A primeira trata do referencial teórico e da metodologia adotados nas análises. A segunda busca captar as condições materiais que contribuíram para a expansão da pós-graduação nessas IES no período em tela e a terceira seção trata da análise das condições simbólicas.

\section{Referencial teórico e metodologia}

As análises partiram das noções de campo, de capital simbólico e de habitus desenvolvidas pelo sociólogo francês Pierre Bourdieu.

Para Bourdieu (2017), os diversos campos sociais, enquanto microcosmos da sociedade, embora não sejam necessariamente análogos, guardam em si certas propriedades comuns em termos de estrutura e lógicas próprias de funcionamento.

Os campos sociais são espaços onde os agentes disputam pela definição do que é válido, e, para tanto, lançam mão de estratégias orientadas para conservação ou subversão de suas estruturas, conforme a posição/volume de capital do agente.

Enquanto subcampo do campo universitário, a pós-graduação brasileira está inscrita nesse contexto e é caracterizada pela priorização da pesquisa científica e de seus produtos.

A posse de capital valorizado nesse campo, assim como nos demais campos sociais, pressupõe legitimidade para falar e impor significações. Isso se dá como efeito simbólico do reconhecimento que os agentes têm sobre o outro e sobre suas ações. Quanto maior o volume global de capital, maior é a diferenciação ou distinção do agente no campo (BOURDIEU, 2007).

O capital simbólico de um indivíduo, grupo ou instituição possui dimensão relacional e coletiva e por essa razão expressa "[...] antes de tudo, o estatuto simbólico em sua dimensão mais concreta, que corresponde ao fato de ser 'reconhecido' e 'valorizado' ('considerado', 'apreciado', 'amado', etc.).” (LEBARON, 2017, p. 102).

O capital de prestígio intelectual, enquanto forma de manifestação de capital simbólico no campo universitário, denota crédito específico junto aos pares e refere-se à contribuição do 
pesquisador para o progresso da ciência (BOURDIEU, 2017). No campo da pós-graduação, esse é concretizado por meio da produção intelectual qualificada do agente, dos projetos de pesquisa desenvolvidos, das participações em redes de colaboração, conferências e outras atividades características do pesquisador e valorizadas no processo avaliativo da CAPES.

Para além do esforço intelectual do agente, o acúmulo de capital de prestígio intelectual também está relacionado à sua circulação no campo acadêmico da pós-graduação.

O capital de poder político institucional, como forma de capital simbólico político ou temporal, é diretamente vinculado à ocupação de posições de poder dentro de instituições como a própria universidade, a CAPES, o CNPq, fundações estaduais de pesquisa, e outros.

O poder político institucional universitário pode ser representado pelos cargos de reitor, vice-reitor e de pró-reitor que dão acesso, inclusive ao Conselho Universitário, instância máxima de decisão na instituição.

Além das noções de campo e de capital, há a noção de habitus, que foi retomada em razão da "[...] vontade de lembrar que, ao lado da norma expressa e explícita ou do cálculo racional, existem outros princípios geradores das práticas” (BOURDIEU, 2004, p. 96).

Esses princípios geradores de práticas, ou instâncias de valor, são refletidos em disposições que levam os agentes sociais a agir e a se comportar de determinada forma em determinadas situações no campo, em conformidade com o habitus por ele incorporado.

Assim, as noções de campo, de habitus e de capital contribuem para apreender os condicionantes da relação entre políticas federais para a expansão da educação superior e a ação do agente docente que circula no campo da pós-graduação, que em determinado momento, irá ocupar, ou não, posições de poder na esfera institucional universitária.

As análises, feitas à luz da literatura da área, se deram também, com base em documentos e estatísticas oficiais. Os dados contribuíram para apreender as condições materiais para a expansão da pós-graduação nas universidades federais em MS.

A orientação institucional, no sentido de agregar capital simbólico à atuação no campo da pós-graduação, foi apreendida com base em documentos institucionais das duas IES. Além disso, buscou-se captar a atuação do agente docente no campo da pós-graduação por meio de uma amostra de programas selecionados a partir dos seguintes critérios:

- Que o programa pertencesse a uma das duas universidades federais em MS;

- Um programa de cada grande área de conhecimento da CAPES;

- Programas que tivessem maior nota, ou que, pelo menos tivessem nota quatro;

- Programa de pós-graduação na modalidade acadêmica. 
Definiu-se, também, que os docentes dos programas deveriam possuir vínculo funcional-administrativo com a instituição de origem do programa de pós-graduação, atuar em apenas um programa da amostra e estar credenciado como permanente no ano de 2018.

Com base nesses critérios, foram selecionados 138 docentes de programas de pósgraduação das duas universidades federais sul-mato-grossenses, dos quais analisou-se informações da produção intelectual de artigos em periódicos, participação em bancas de defesa de dissertação/tese, bem como participação em comitês da CAPES.

\section{Condições materiais para expansão da pós-graduação em universidades federais sul- mato-grossenses}

A política pública educacional é entendida como uma série de ações e intenções de gestores, que são materializadas sob a forma de leis, programas e projetos, que buscam equalizar temáticas que ocupam a agenda pública, como é o caso da ampliação do acesso à educação superior (PALUMBO, 1994).

Assim, embora não se tenham superado as tendências neoliberais nas políticas públicas educacionais (GREGÓRIO; MANCEBO, 2019), a implementação dos programas Expandir e REUNI, que se deu a partir de 2003, permitiu certa recuperação das universidades federais, sobretudo em termos de financiamento e de pessoal.

Esse movimento, conforme mencionado anteriormente, refletiu no aumento da oferta de educação superior, inclusive em IES localizadas fora do eixo Sul-Sudeste, como é o caso das universidades federais em MS.

A tabela 1 mostra o incremento no número de matrículas de graduação presencial e de pós-graduação nas universidades federais em MS no período de 2003 até 2018: 
Tabela 1 - Evolução do total de matrículas em universidades federais - MS (2003/2018)

\begin{tabular}{ccc}
\hline Ano & Matrículas Graduação presencial & Matrículas Pós-Graduação stricto sensu \\
\hline 2003 & 14.660 & 433 \\
\hline 2018 & 25.620 & 2.640 \\
\hline 7 & 75 & 510 \\
\hline
\end{tabular}

Fonte: Elaboração própria com base nos dados disponíveis no INEP e GEOCAPES. Disponível em: https://geocapes.capes.gov.br/geocapes/ e http://inep.gov.br/web/guest/sinopses-estatisticas-daeducacao-superior. Acesso em: 30 out. 2020.

Os dados da tabela 1 evidenciam o aumento em 75\% nas matrículas de graduação presencial e de 510\% nas matrículas de pós-graduação nas IFES de MS no período em tela.

Apesar do avanço contínuo do setor privado na oferta de educação superior brasileira (CAMARGO; ARAÚJO, 2018), a expansão de matrículas em universidades federais teve seus efeitos, inclusive, no sentido de aumentar a participação proporcional dessas IES no montante de matrículas de educação superior no Brasil.

Conforme dados constantes na tabela 2, esse movimento também é visualizado no MS:

Tabela 2 - Proporção de matrículas em universidades federais com relação ao total de IES - MS $(2003 / 2018)$

\begin{tabular}{ccc}
\hline Ano & Graduação presencial & Pós-Graduação stricto sensu \\
\hline 2003 & $24 \%$ & $68 \%$ \\
\hline 2018 & $30 \%$ & $75 \%$ \\
\hline
\end{tabular}

Fonte: Elaboração própria com base nos dados disponíveis no censo da educação superior do INEP e GEOCAPES. Disponível em: https://geocapes.capes.gov.br/geocapes/ e

http://inep.gov.br/web/guest/sinopses-estatisticas-da-educacao-superior. Acesso em: 30 out. 2020.

A participação proporcional das universidades federais em MS na oferta de matrículas em cursos de graduação presencial, com relação ao conjunto de IES do estado, igual a $24 \%$ em 2003, aumentou para 30\% em 2018. Da mesma forma, a participação proporcional dessas instituições na oferta de pós-graduação, com relação ao total do estado, aumentou de $68 \%$ para $75 \%$ no mesmo período.

Esses dados explicitam que, embora a expansão nas universidades federais em MS tenha ocorrido nos níveis de graduação e de pós-graduação, o maior impacto se deu com relação ao aumento proporcional da oferta de pós-graduação.

Em 2018, as universidades federais sul-mato-grossenses agregavam $75 \%$ do montante de matrículas em programas de pós-graduação no estado, enquanto a universidade estadual 16\% e as privadas 9\% (BRASIL, 2018a). 
A expressiva expansão de matrículas nas universidades federais em MS somente foi possível pela relativa recuperação que houve no quantitativo de docentes, técnicos ${ }^{2}$ e incremento de infraestrutura no período, principalmente por meio dos programas Expandir e Reuni.

Destaca-se que, com relação à expansão da pós-graduação em universidades federais, o indicador "formação de corpo docente" representa a base material proporcionada pelas políticas expansionistas do poder público no período.

Embora, mais recentemente, a CAPES venha incluindo outros instrumentos para avaliação (LEITE et al., 2020; MAGALHÃES; REAL, 2020), a produção intelectual docente, especialmente por meio de artigos em periódicos qualificados permanece determinante para credenciamento e recredenciamento dos programas de pós-graduação no Brasil

São os docentes que, via de regra, elaboram e coordenam a proposta de novos cursos para avaliação da CAPES. Os mesmos gerenciam os programas de pós-graduação e são responsáveis pelas informações preenchidas na Plataforma Sucupira ${ }^{3}$. Além, é claro, do fato de que orientam e ministram disciplinas nos programas de pós-graduação.

O aumento de pessoal nas universidades federais, sobretudo de doutores, proporcionado pelas políticas expansionistas do período, embora não tenha acompanhado o crescimento de matrículas no setor (TRINDADE PRESTES; JEZINE; SCOCUGLIA, 2012) contribuiu para o incremento da participação das IFES na oferta de graduação e de pósgraduação.

A tabela 3 traz o incremento no total de funções docentes nas universidades federais sul-mato-grossenses dos anos de 2003 até 2018.

Tabela 3 - Evolução do total de funções docentes (em exercício e afastados) em universidades federais MS (2003/2018)

\begin{tabular}{cccc}
\hline Ano & Total Docentes & Docentes tempo integral & Docentes com doutorado \\
\hline 2003 & 1.052 & 721 & 305 \\
\hline 2018 & 2.496 & 2081 & 1701 \\
\hline$\%$ & 137 & 189 & 458 \\
\hline
\end{tabular}

Fonte: Elaboração própria com base nos dados disponíveis no censo da educação superior do INEP. Disponível em: http://inep.gov.br/censo-da-educacao-superior. Acesso em: 31 out. 2020.

\footnotetext{
${ }^{2}$ Com base nos dados divulgados pelo INEP, observa-se que houve aumento de cerca de $186 \%$ no número de técnicos das IFES brasileiras entre 2003 e 2018. Nesse sentido ver: http://portal.inep.gov.br/web/guest/sinopses-estatisticas-da-educacao-superior. Acesso em: 5 ago. 2020.

${ }^{3}$ Plataforma Sucupira é a base de dados utilizada pela CAPES para avaliação e acompanhamento dos programas que compõem o SNPG. Disponível em: https://sucupira.capes.gov.br/sucupira/. Acesso em: 5 dez. 2020.
} 
Conforme dados da tabela, o incremento no número de funções docentes nas universidades federais em MS foi de 137\% no período que compreendeu os anos de 2003 até 2018. Nesse período, o acréscimo no número de docentes contratados com regime de tempo integral (dedicação exclusiva) e de docentes com doutorado foi de $189 \%$ e de $458 \%$, respectivamente.

Com isso, a proporção de docentes com dedicação exclusiva nas universidades federais de MS, com relação ao total, aumentou de 69\% em 2003, para 83\% em 2018 e a proporção de docentes com doutorado de $29 \%$ para $68 \%$ no mesmo período.

Isso vai ao encontro de exigências de áreas de avaliação da CAPES que determinam que, pelo menos, parte dos docentes dos quadros de programas de pós-graduação tenham vínculo funcional administrativo de dedicação exclusiva com a IES, além do título de doutor para todos os docentes, quando se trata de programa na modalidade acadêmica.

Cumpre destacar que a modalidade acadêmica foi a mais enfatizada nas universidades federais sul-mato-grossenses no período, e ainda responde pela grande maioria de matrículas em programas de pós-graduação. Os programas na modalidade acadêmica agregam $88 \%$ do total de matrículas na pós-graduação em MS.

Ao cotejar dados do GEOCAPES e INEP (BRASIL, 2018a; 2018b), verifica-se que pouco mais da metade do total de docentes com doutorado das universidades federais em MS fazia parte da pós-graduação até 2018. O aumento no número de doutores contribuiu para que, ao longo dos anos, triplicasse o número de programas de pós-graduação nessas IES (de 15 programas em 2003 para 56 em 2018).

Com isso, o número de matrículas em cursos de graduação presencial para cada matrícula em programa de pós-graduação nas universidades federais em MS, que era igual a 34 no ano de 2003, passou para 10 em 2018. Esses dados evidenciam a ênfase para a expansão da pós-graduação nas IES.

Destaca-se, no entanto, que diferentemente do que ocorre com a graduação, em que a criação de novas universidades e campi pressupõe abertura de cursos e criação de novas vagas, isso não ocorre com a pós-graduação.

A criação de novos programas/cursos de pós-graduação obedece a regras distintas daquelas relacionadas à graduação (BRASIL, 2017). Programas novos somente são autorizados após passarem por avaliação da CAPES, mesmo para as universidades, que possuem autonomia universitária, conforme as normas vigentes.

O aumento no quantitativo docente foi de fundamental importância para a expansão da pós-graduação nessas instituições. No entanto, por si só, esse aumento não implicaria na 
expansão da pós-graduação. Destaca-se aqui a lógica de funcionamento do campo universitário, em que docentes e gestores atuam para concretizar um projeto de expansão da pós-graduação nas IES, com base no capital instituído no campo acadêmico, que agrega capital simbólico a esse tipo de atuação. Essa é a discussão da seção que segue.

\section{Condições simbólicas para expansão da pós-graduação nas universidades federais sul- mato-grossenses}

O processo de abertura de novos programas de pós-graduação depende da atuação docente em pesquisa e divulgação de seus produtos. Conforme mencionado anteriormente, dentre os itens considerados para autorização de funcionamento de programas de pósgraduação pela CAPES, a produção intelectual docente tem tido maior peso.

Nesse sentido, a expansão é apoiada pela própria constituição do campo acadêmico que agrega valor à participação docente na pós-graduação em universidades públicas. Isso passa pelas condições simbólicas, as quais se deu a expansão da pós-graduação em universidades, sobretudo em termos de capital de prestígio intelectual e de poder político institucional.

A análise dos dados amostrais da pesquisa aponta que a ação institucional foi orientada para a captação de docentes com perfil de pós-graduação e a manutenção desse habitus nas universidades federais sul-mato-grossenses.

Conforme se observou nos dados colhidos nos currículos Lattes dos docentes da amostra, mais de $78 \%$ ingressaram a partir de 2003. Desse total, apenas $11 \%$ não possuía doutorado quando ingressou na instituição. O gráfico a seguir ilustra o total de docentes da amostra por ano de obtenção do doutorado.

Gráfico 1 - Total de docentes da amostra por ano de obtenção do doutorado (ano base 2018)

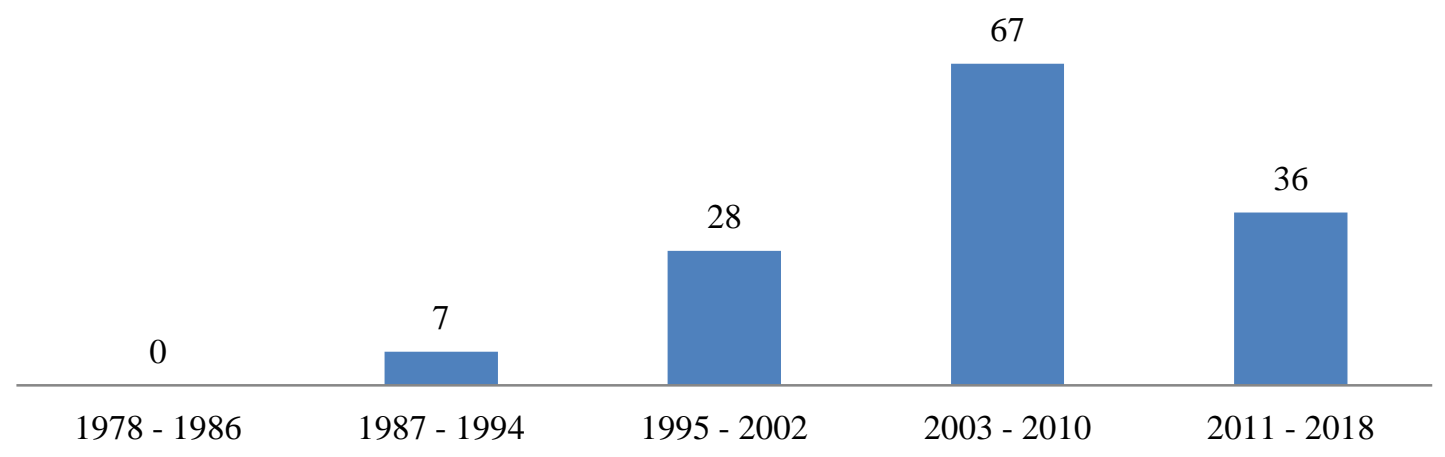

Fonte: Elaboração própria com base nos dados do Currículo Lattes dos docentes. Disponível em: http://lattes.cnpq.br/. Acesso em: 30 mar. 2019. 
Os dados do gráfico 1 explicitam que todos os docentes obtiveram sua titulação no período compreendido entre os anos de 1987 e 2018, muito embora, também tenham contratações datadas do período de 1978 até 1986.

Isso evidencia que, assim como as instituições, o quadro de doutores da pós-graduação das universidades federais em MS é jovem, com maioria contratada (78\%) e titulada (75\%) a partir de 2003. O campo da pós-graduação das referidas IES é majoritariamente composto por docentes recém-doutores.

A despeito disso, para além de sua formação inicial, do total de docentes da amostra, 47\% possuía experiência em pós-graduação antes de ingressar no magistério da respectiva universidade. Esses ingressaram nas instituições já com o doutorado e a partir de 2003.

A maioria dos docentes com experiência anterior na pós-graduação foi bolsista de órgão de fomento nacional, atuando como professor visitante, recém-doutor, pós-doutorado ou bolsa do programa de Desenvolvimento Científico e Tecnológico Regional (DCR), no período compreendido entre a conclusão do doutorado e o ingresso na respectiva universidade.

Isso indica que, a partir de 2003, há maior planejamento para a expansão da pósgraduação nas universidades federais em MS, não só por parte dos programas de pósgraduação, mas também dos gestores institucionais. Nessas IES, as contratações de professores foram direcionadas, selecionando preferencialmente docentes que já possuíam doutorado e experiência na pós-graduação.

Verifica-se o esforço por parte de instituições/agentes no sentido de buscar maior qualificação docente. As novas contratações foram direcionadas para titulados com doutorado, ao mesmo tempo em que, docentes buscaram sua qualificação quando já pertenciam aos quadros das universidades. Considera-se que a existência de recém-doutores foi significativa para ampliar uma cultura voltada para o habitus da pós-graduação nas IES.

Para além do título de doutor, a experiência docente em programa de pós-graduação antes de seu ingresso na instituição garantiu que o recém-contratado já estivesse mais habituado à divulgação dos produtos gerados por suas pesquisas. E por essa razão, esses professores foram incluídos mais rapidamente nos quadros dos programas de pós-graduação.

Os dados amostrais apontam que quanto mais recente o ingresso do docente da amostra na universidade federal em MS, mais rápida sua inclusão no quadro permanente da pós-graduação. Para os docentes da amostra que ingressaram na instituição entre 2003 e 2010, a média de tempo entre sua inclusão na IES e seu respectivo credenciamento no quadro 
permanente do programa de pós-graduação foi de aproximadamente dois anos. Essa média de tempo para os docentes que ingressaram nas IES a partir de 2011 é de menos que um ano.

Isso porque o habitus da pós-graduação é incorporado desde a formação. Os dados explicitam que recém-doutores com perfil para pós-graduação, ao serem incluídos nas IES, buscaram se mobilizar em torno do capital simbólico atribuído à atuação no campo da pósgraduação da universidade.

Nesse sentido, observa-se que os agentes ocupantes de altos cargos de gestão institucional nas universidades federais sul-mato-grossenses, ao priorizarem a contratação de docentes com o habitus da pós-graduação - aqui evidenciado pela experiência anterior - foram capazes de agregar valor junto a um cenário nacional favorável, em que se multiplicam o número de doutores titulados a cada ano.

O capital simbólico atribuído à participação na pós-graduação é visualizado no campo universitário institucional, inclusive pelo aumento de docentes da pós-graduação nas instâncias de poder político ao longo dos anos nas universidades federais sul-mato-grossenses.

Com relação aos docentes que ocuparam cargos de reitor, vice-reitor ou pró-reitor durante a gestão de reitorado, em curso no ano de 2018, os dados analisados na pesquisa apontaram que, comparado às gestões anteriores, houve aumento da presença de agentes com vínculo permanente com a pós-graduação (mais de $80 \%$ do total), dos quais todos com título de doutor

Nesse sentido, há um movimento em torno da conversão de capital de prestígio intelectual em capital de poder político institucional universitário nas IES federais, materializado pela ocupação de cargos de reitor, vice-reitor ou pró-reitor ${ }^{4}$.

Isso permitiu que os gestores se valessem de estratégias no sentido de induzir um ambiente favorável para a expansão da pós-graduação nas universidades federais em MS.

A significativa expansão da pós-graduação nessas instituições, em termos quantitativos, também foi induzida pelas estratégias dos gestores para agregar capital simbólico às atividades relacionadas à pós-graduação, especialmente pela busca de manutenção do habitus da pós-graduação pelo agente.

\footnotetext{
${ }^{4}$ Isso vinha ocorrendo, pelo menos até o ano de 2018, em que ainda se mantinha, por parte do poder público central, a nomeação do reitor conforme colocação na lista tríplice encaminhada pelas respectivas IES federais. Isso deixou de ser prática desde $2019 . \quad$ Nesse sentido ver: https://www1.folha.uol.com.br/educacao/2020/12/reitores-eleitos-e-nao-empossados-por-bolsonaroquestionam-mec.shtml. Acesso em: 8 dez. 2020.
} 
Conforme analisado na pesquisa, documentos oficiais das instituições, particularmente aqueles aprovados nos Conselhos Universitários, explicitam a intenção de se estabelecer um ambiente favorável para a pesquisa por meio da pós-graduação nas universidades.

Os Planos de Desenvolvimento Institucionais (PDIs) das IES enfatizam a preocupação quanto à produção intelectual, bem como a priorização pela contratação de docentes com título de doutor e em regime de dedicação exclusiva. $\mathrm{O}$ trecho a seguir transcrito do PDI de uma das universidades federais do MS ilustra essa questão:

\begin{abstract}
Vislumbra-se que, por meio do Plano Nacional da Educação (2011-2020), com as metas relativas à educação superior ali esboçadas, adentrar-se-á a essa etapa de consolidação das diferentes áreas de conhecimento na UFGD, não somente com a ampliação da graduação, presencial e a distância, como também com propostas de cursos de mestrados e doutorados. Essa é uma condição estratégica para a UFGD, seja para ampliação das vagas, seja porque o ensino de pós-graduação tem sido importante para a fixação de doutores em uma universidade que está instalada no Centro-Oeste brasileiro (UFGD, 2013, p. 20).
\end{abstract}

Adequações para o atendimento às exigências/recomendações de agências de fomento de pós-graduação e de pesquisa estão presentes nos editais de distribuição de cotas de bolsas de iniciação científica, nos regulamentos e Editais de concurso público para ingresso na carreira do magistério superior, bem como nos regulamentos de pesquisa das universidades federais sul-mato-grossenses.

Nesses documentos, além de outras atividades valorizadas no contexto da pósgraduação, observa-se a ênfase para a classificação com base na produção intelectual docente, aferida por meio do Qualis-periódicos ${ }^{5}$, em conformidade com a avaliação realizada pela CAPES. O trecho a seguir, transcrito do PDI de uma das universidades, elucida a ênfase para a produção intelectual, inclusive com relação ao processo seletivo para ingresso na instituição:

A Prova de Títulos, exigida para os candidatos de todas as Classes, terá como objetivo avaliar o aperfeiçoamento profissional, crescimento de sua produção intelectual e a atualização científica dentro do seu projeto pessoal de vida, evidenciando os trabalhos acadêmicos do candidato em relação às atividades de ensino, de pesquisa, de extensão e de administração acadêmica (UFMS, 2010, p. 74).

A adesão aos critérios de avaliação da CAPES com a pontuação somente para projetos com fomento externo, utilização do Qualis-periódicos na ficha relativa à prova de títulos das

\footnotetext{
${ }^{5} \mathrm{O}$ Qualis-Periódicos é uma ferramenta usada para classificar a produção científica dos programas de pósgraduação. Nesse sentido ver: http://capes.gov.br/avaliacao/instrumentos-de-apoio/qualis-periodicos-eclassificacao-de-producao-intelectual. Acesso em: 4 nov. 2019.
} 
IES, está explicitada nos regulamentos do concurso docente (UFMS, 2016, 2018) e nos respectivos Editais ${ }^{6}$.

Observa-se, com isso, a adoção de variados mecanismos de gestão para induzir o habitus da pós-graduação nas universidades federais em MS, inclusive desde a contratação.

Neste contexto, cabe destacar a ação docente que trabalha para se adequar às exigências avaliativas da CAPES. Isso é explicitado no aumento da produção intelectual qualificada do docente - para o caso da amostra utilizada na pesquisa, observou-se que em 2013 a parcela de artigos publicados em periódicos dos estratos superiores do Qualisperiódicos ${ }^{7}$ era de $62 \%$, em 2018 esse percentual é igual a 68\% (ver tabela 4).

Dentre as variadas atividades requeridas ao docente da pós-graduação, inclui-se o aumento da participação/coordenação de projeto de pesquisa, inclusive com fomento externo. Conforme dados constantes nos respectivos Currículos Lattes dos docentes da amostra, a participação desses na condição de coordenador de projeto de pesquisa, desde sua titulação, se deu em 1.180 projetos, dos quais 582 contavam com algum tipo de financiamento externo.

Todo esse movimento de indução da expansão da pós-graduação nas universidades federais em MS, por meio de seu campo acadêmico, engendrou sua expressiva expansão em curto período de tempo.

Por outro lado, apesar da significativa expansão quantitativa no período, os dados evidenciam que, de acordo com o formato avaliativo da CAPES, os agentes do campo da pósgraduação das universidades federais em MS ainda precisam consolidar sua expansão qualitativa.

A tabela a seguir mostra a evolução no quantitativo de produção intelectual publicada pelos docentes, distribuído conforme classificação do Qualis-periódicos para o ciclo quadrienal que iniciou em 2013 e o período que compreendeu a primeira metade do próximo ciclo $^{8}$.

\footnotetext{
${ }^{6}$ Nesse sentido ver: https://cs.ufgd.edu.br/concursos/. Acesso em: 31 out. 2019.

7 Até 2018, os estratos A1, A2, B1, B2 eram considerados estratos superiores do Qualis-periódicos. Nesse sentido ver: https://rbpg.capes.gov.br/index.php/rbpg/article/view/947. Acesso em 20 out. 2020.

${ }^{8}$ Por uma questão de padrão optou-se por utilizar o modelo de distribuição de classificação do Qualis periódico utilizado dos anos de 2003 até 2018 (ciclo quadrienal (2003-2016) e primeira metade do próximo ciclo avaliativo (2017-2020)), as mudanças no Qualis, bem como as novas classificações foram apresentadas somente a partir de 2019. Nesse sentido ver: https:/www.gov.br/capes/pt-br/centrais-deconteudo/documentos/avaliacao/ORIENTAES_PROCESSO_AVALIATIVO_INFORMATIVO_1.pdf. Acesso em: 5 nov. 2020.
} 
Tabela 4 - Produção intelectual publicada no formato de artigos em periódicos conforme informado no Currículo Lattes dos docentes da amostra (2013-2018)

\begin{tabular}{cccccccc}
\hline Ano & Total & Qualis A1 & Qualis A2 & Qualis B1 & Qualis B2 & $\begin{array}{c}\text { Estratos } \\
\text { inferiores }\end{array}$ & $\begin{array}{c}\text { Sem classificação } \\
\text { para a área }\end{array}$ \\
\hline 2013 & 468 & 18 & 41 & 118 & 113 & 151 & 27 \\
\hline 2014 & 531 & 26 & 44 & 165 & 92 & 182 & 22 \\
\hline 2015 & 436 & 26 & 60 & 117 & 97 & 116 & 21 \\
\hline 2016 & 543 & 43 & 73 & 129 & 153 & 128 & 16 \\
\hline 2017 & 531 & 54 & 61 & 122 & 146 & 109 & 49 \\
\hline 2018 & 572 & 77 & 66 & 122 & 123 & 144 & 48 \\
\hline$\%$ & 22 & 328 & 61 & 3 & 9 & -5 & 40 \\
\hline
\end{tabular}

Fonte: Elaboração própria com base nos dados do Currículo Lattes dos docentes. Levantamento realizado em agosto de 2019.

Verificou-se que houve o aumento em $22 \%$ na produção intelectual global docente dos anos de 2013 até 2018. Nesse período, também, houve aumento em 328\% no número de artigos publicados em periódicos qualificados com A1 e em $61 \%$ no número de artigos publicados em periódicos qualificados com A2.

Os dados explicitam melhora nos indicadores de produção da amostra de programas de pós-graduação das duas universidades federais sul-mato-grossenses, que se deu, sobretudo, por meio do progressivo aumento da produção intelectual em periódicos mais qualificados.

No entanto, por tratar-se de programas relativamente consolidados, de acordo com os parâmetros do estado de MS, considera-se que ainda é baixa a produção nos periódicos A1 e A2. A produção intelectual docente nesses periódicos correspondia a pouco mais de $25 \%$ do total global da produção intelectual da amostra em 2018.

Isso leva em conta que a amostra de programas de pós-graduação das universidades federais sul-mato-grossenses contempla parte dos programas mais bem classificados pela avaliação da CAPES no estado. Dos nove programas selecionados, quatro possuem nota cinco, um possui nota seis e os demais nota quatro9.

Do total de docentes da amostra, apenas $17 \%$ possui solicitação ou registro de patente em seu currículo Lattes, e, ainda assim, de forma compartilhada com um ou mais colegas do mesmo ou de distintos programas de pós-graduação. Isso explicita a baixa produção em termos de inovação científica no campo da pós-graduação sul-mato-grossense, embora isso seja uma tendência em todo cenário nacional (GAZZOLA; FENATI, 2010).

Conforme registrado nos respectivos currículos Lattes, a participação docente em bancas de dissertação/tese de outras IES também é baixa com relação ao total de participações.

\footnotetext{
${ }^{9}$ Lembrando que, como resultado da avaliação quadrienal 2017, o estado de MS possui um programa nota 6, nove com nota 5 e não há programas com nota 7. (GEOCAPES, 2018).
} 
Isso pode ser visualizado no gráfico a seguir:

Gráfico 2 - Participação dos docentes da amostra de programas de pós-graduação das universidades federais sul-mato-grossenses em bancas de defesa de dissertação/tese internas e externas às instituições desde o ingresso como docente da universidade (1995-2018)

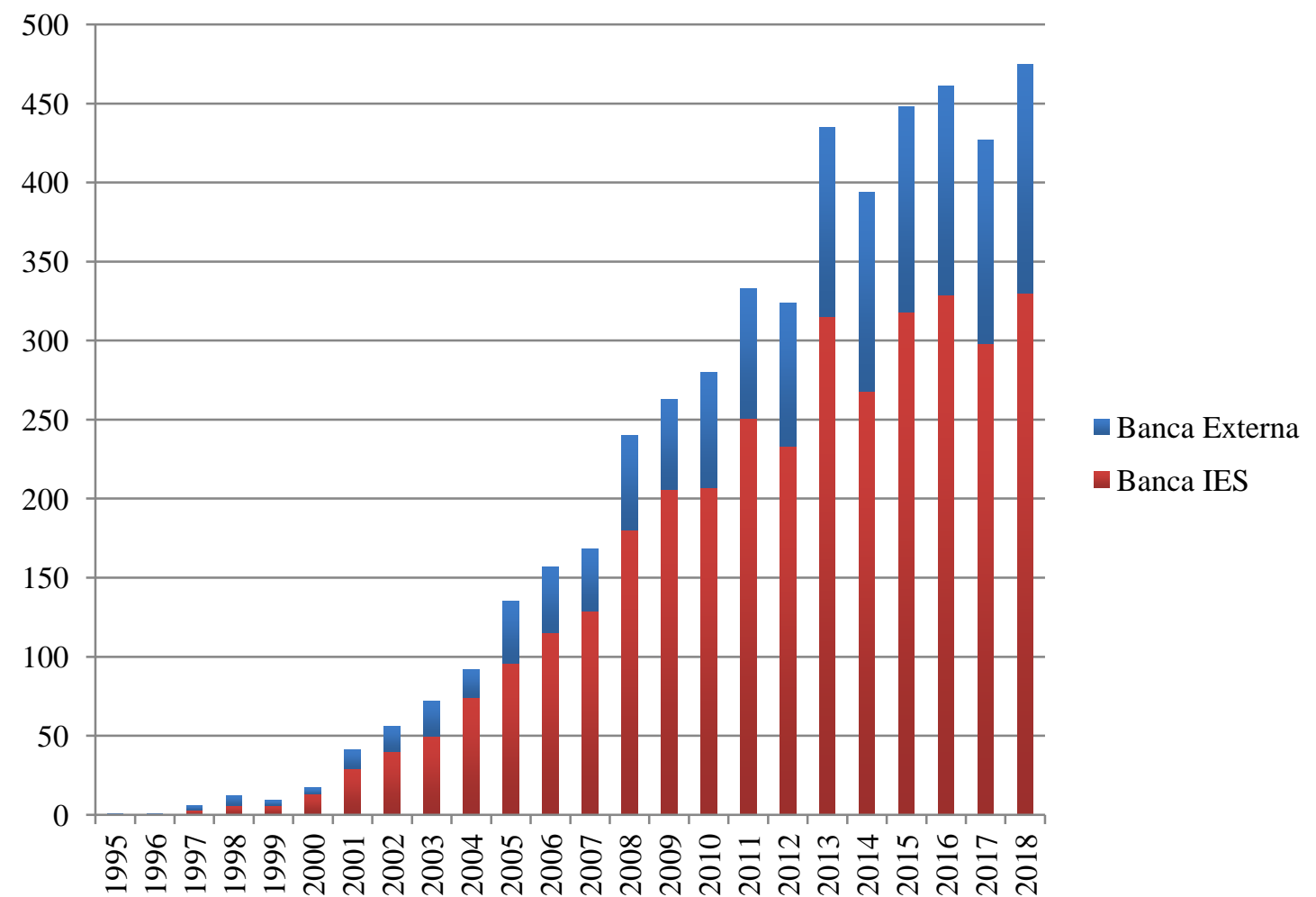

Fonte: Elaboração própria com base nas informações colhidas de 31 julho até 3 agosto de 2019 nos currículos Lattes dos docentes da amostra.

Nota-se que a participação docente da amostra em bancas de dissertação/tese em programas de pós-graduação de outras IES é igual à cerca de $30 \%$ do total de participações em bancas. Essa proporção é baixa, especialmente se considerando que a grande maioria das participações externas se deu em IES na mesma cidade onde está localizada a universidade de origem do programa ou em cidades da mesma unidade da federação.

Isso explicita que, apesar da significativa expansão da pós-graduação nas universidades federais em MS, a circulação de seus agentes no campo da pós-graduação em outras unidades da federação, ou mesmo internacionalmente, é reduzida. Bourdieu (2017) declara que:

Somente um conjunto de monografias permitiria apreender a lógica das trocas em que entram os universitários por ocasião das bancas de tese (aquele que pede a participação de um colega na banca de uma tese que ele orientou se obriga tacitamente a conceder a reciprocidade e entra, portanto, no circuito de trocas contínuas) [...]. Isso é sem dúvida o que faz com que a lógica da acumulação do poder tome a forma de uma engrenagem de obrigações que engendram as 
obrigações, de uma acumulação progressiva de poderes que lembra as solicitações geradoras de poder. (BOURDIEU, 2017, p. 133).

Nesse sentido, a baixa participação em bancas de defesa de dissertação/tese também explicita a restrita capacidade de circulação do agente no campo. Isso, embora possa estar atrelada ao capital intelectual do agente, também tem correlação com sua inserção política no campo acadêmico da pós-graduação.

Observa-se, também, a reduzida participação dos docentes da amostra em Comitês da CAPES. Conforme levantamento feito nos respectivos currículos Lattes, menos de $4 \%$ do total da amostra tem ou teve algum tipo de participação em comitê científico do órgão gestor da pós-graduação brasileira.

A baixa circulação dos docentes de programas de pós-graduação das universidades federais do MS nas demais instituições que compõem o campo acadêmico universitário, sobretudo com relação ao campo de poder, representado pela CAPES, explicita a fragilidade do capital de prestígio intelectual externo desses docentes.

Considerando que a avaliação é comparativa, esses fatores refletem no distanciamento dos parâmetros do órgão gestor e na respectiva pontuação dos programas que não alcançam os estratos superiores da avaliação. No ano de 2018, do total de 72 programas de pós-graduação credenciados pela CAPES em MS, apenas nove programas possuíam nota cinco (sete nas universidades federais e dois em universidades privadas), apenas um programa possuía nota 6 (em universidade federal) e não existiam programas classificados com nota 7 pela avaliação da CAPES no estado.

A restrita circulação do agente pertencente aos quadros da pós-graduação das universidades federais sul-mato-grossenses no campo da pós-graduação nacional, ou mesmo internacional, se dá, portanto, em termos de espaços de poder - pela baixa participação nas instâncias decisórias da CAPES - e em termos de capital de prestígio intelectual - evidenciado pela baixa participação em bancas de defesa de programas de pós-graduação de outras IES e pelo menor acúmulo de produção em periódicos classificados em estratos A1 e A2 do Qualis/CAPES.

Isso é manifesto pelas dificuldades de agentes do campo da pós-graduação de instituições fora dos grandes centros demográficos brasileiros de agregarem formas de capital de prestígio intelectual externo em suas atividades no campo da pós-graduação, cuja grande circulação permanece restrita às IES do eixo Sul-Sudeste.

Entre os diversos aspectos que envolvem as disputas no campo da pós-graduação, pode-se destacar, no caso específico do MS, que se trata de um corpo docente em sua maioria 
com pouco tempo de formação e, portanto, jovem, vinculados a instituições também jovens e com menos inserção nos espaços de visibilidade acadêmico-científica.

Em que pese a progressiva maturidade do corpo de docentes das universidades federais sul-mato-grossenses, o fato de a avaliação da pós-graduação ser comparativa implica na dificuldade de se configurarem condições simbólicas que viabilizem o acesso aos estratos superiores da avaliação por parte dos programas de pós-graduação dessas instituições.

\section{Considerações finais}

Conforme se observou nos dados apresentados, a característica à qual se reveste a expansão da pós-graduação nas universidades federais em MS indica que a expansão ocorrida na pós-graduação a partir de 2003, se deu pela combinação de políticas governamentais indutoras da expansão da educação superior - em que proporcionou certa recuperação das universidades federais, especialmente em termos de corpo docente - de ações de indução por parte dos gestores universitários no contexto das instituições e da própria ação docente, particularmente pela manutenção do habitus da pós-graduação adquirido em sua formação.

Nesse contexto, há a centralidade da ação docente, que se envolve em todos os processos que compreendem a pós-graduação, sobretudo em termos de produção intelectual. A busca por capital simbólico do corpo docente com perfil delineado pelo habitus da pósgraduação contribui para a manutenção do campo da pós-graduação brasileira, cuja constituição induz sua circulação nas esferas de decisão, particularmente pelo formato de avaliação por pares adotado pela CAPES.

Observa-se que esse movimento engendrou a expansão da pós-graduação nas IES. No entanto, com base no modelo de avaliação conduzido pela CAPES, esse não foi capaz de consolidá-la em termos de sua expansão qualitativa.

Isso evidencia o aprofundamento das assimetrias regionais, quando se observa que programas mais qualificados do ponto de vista do órgão gestor, permanecem concentrados nos grandes centros demográficos do país. Essa questão se complexifica na medida em que são adotados critérios meritocráticos pela CAPES para a distribuição de financiamento aos programas de pós-graduação.

Capital leva ao capital. Se os agentes do campo da pós-graduação das universidades federais sul-mato-grossenses não possuem volume de capital de prestígio intelectual ou de poder político que permita sua maior circulação no campo da pós-graduação, tende a 
permanecer, também, a impossibilidade de acessarem os estratos superiores de avaliação do órgão gestor.

Essa situação somente poderia ser minimizada com políticas mais efetivas de combate às assimetrias regionais em termos qualitativos, capazes de induzir a circulação no campo da pós-graduação em todas as regiões do país e criar mecanismos para garantir maior inserção desses agentes nas instâncias decisórias. Somente novas pesquisas poderiam propor ações nesse sentido, considerando que os recursos para tal finalidade são caros e estão cada vez mais raros, inclusive devido a novas lógicas adotadas pelo poder central nas políticas recentes.

\section{Referências}

AZEVEDO, Mário Luiz Neves; CATANI, Afrânio Mendes. Políticas públicas para a educação superior no Brasil (1990-2020): da universidade operacional ao programa FUTURE-SE. Universidades, Ciudad de México, v. 71, n. 85, p. 33-52, set. 2020. Disponível em: http://udualerreu.org/index.php/universidades/article/view/275. Acesso em: 4 out 2020.

BRASIL. Decreto n. 6.096, de 24 de abril de 2007. Institui o Programa de Apoio a Planos de Reestruturação e Expansão das Universidades Federais - REUNI. Brasília, 2007. Disponível em: http://www.planalto.gov.br/ccivil_03/_ato2007-2010/2007/decreto/d6096.htm. Acesso em: 12 ago. 2020.

BRASIL. Decreto n. 9.235, de 15 de dezembro de 2017. Dispõe sobre o exercício das funções de regulação, supervisão e avaliação das instituições de educação superior e dos cursos superiores de graduação e de pós-graduação no sistema federal de ensino. Brasília: 2017. Disponível em: http://www.planalto.gov.br/ccivil_03/_Ato20152018/2017/Decreto/D9235.htm\#art107. Acesso em: 7 jun. 2020.

BRASIL. Ministério_da Educação. Instituto Nacional de Estudos e Pesquisas Educacionais Anísio Teixeira (INEP). Sinopse estatística da sducação superior. Brasília: INEP, 2018 a. Disponível em: http://portal.inep.gov.br/web/guest/sinopses-estatisticas-da-educacao-superior. Acesso em: 31 out. 2020.

BRASIL. Ministério da Educação. Coordenação de Aperfeiçoamento de Pessoal de Nível Superior - CAPES. Sistema de informações georreferenciadas: GEOCAPES - Dados estatísticos, Brasília: CAPES, 2018b. Disponível em: https://geocapes.capes.gov.br/geocapes/. Acesso em: 31 out. 2020.

BOURDIEU, Pierre. A distinção: crítica social do julgamento. São Paulo;Porto Alegre: EDUSP; Zouk, 2007.

BOURDIEU, Pierre. Coisas ditas. São Paulo: Brasiliense, 2004.

BOURDIEU. Pierre. Homo academicus. 2. ed. Florianópolis: UFSC, 2017. 
CAMARGO, Arlete Maria Monte; ARAÚJO, Israel Martins. Expansão e interiorização das universidades federais no período de 2003 a 2014: perspectivas governamentais em debate. Acta Scientiarum Education, Maringá, v. 40, n. 1, p. 1-11, 2018. Disponível em: https://www.redalyc.org/articulo.oa?id=303357588004. Acesso em: 31 out. 2020.

CAMPOS, Douglas Aparecido. A avaliação da educação superior diante de uma colonialidade do saber e do poder: a participação política discente. Avaliação, Campinas; Sorocaba, v. 22, n. 1, p. 179-199, abr. 2017. Disponível em: https://www.scielo.br/scielo.php?script=sci_arttext\&pid=S141440772017000100179\&lng=en\&nrm=iso. Acesso em: 20 out 2020.

GAZZOLA, Ana Lúcia Almeida; FENATI, Ricardo. A pós-graduação brasileira no horizonte de 2020. In: BRASIL. Ministério da Educação. Coordenação de Aperfeiçoamento de Pessoal de Nível Superior. Plano Nacional de Pós-Graduação - PNPG 2011-2020, v. 2. Brasília, DF: CAPES, 2010. p. 7-16.

GREGÓRIO, José Renato Bez; MANCEBO, Deise. Produção de ciência e tecnologia e o trabalho do professor empreendedor. Revista Eletrônica de Educação, São Carlos, v. 13, n. 3, p. 903-920, set./dez. 2019. Disponível em: http://www.reveduc.ufscar.br/index.php/reveduc/article/view/3533/886. Acesso em: 7 jun. 2020.

LEBARON, Frédéric. Capital. In: NOGUEIRA, Maria Alice; HEY, Ana Paula; MEDEIROS, Cristina Carta Cardoso de (org.). Vocabulário Bourdieu. Belo Horizonte: Autêntica, 2017. p. 101-103.

LEITE, Denise et al. A autoavaliação na Pós-graduação (PG) como componente do processo avaliativo CAPES. Avaliação, Campinas; Sorocaba, v. 25, n. 2, p. 339-353, ago. 2020.

Disponível em: http://www.scielo.br/scielo.php?script=sci_arttext\&pid=S141440772020000200339\&lng=en\&nrm=iso. Acesso em: 20 out 2020.

MAGALHÃES, Ana Maria Silva; REAL, Giselle Cristina Martins. A evasão no contexto da expansão da pós-graduação stricto sensu: uma discussão necessária. Perspectiva, Florianópolis, v. 38, n. 2, p. 01-18, abr./jun. 2020. Disponível em: https://periodicos.ufsc.br/index.php/perspectiva/article/view/2175-795X.2020.e62019. Acesso em: 21 out 2020 .

MOURA, Mara Águida Porfírio;_PASSOS, Guiomar de Oliveira. A taxa de conclusão de curso da graduação nas universidades federais antes e depois do REUNI: as vicissitudes da implementação da política. Avaliação, Campinas; Sorocaba, v. 24, n. 2, p. 513-525, out. 2019. Disponível em: http://www.scielo.br/scielo.php?script=sci_arttext\&pid=S141440772019000200513\&lng=en\&nrm=iso. Acesso em: 20 maio 2020.

OLIVEIRA, João Ferreira; AMARAL, Nelson Cardoso. La transición política en Brasil y su efecto en la educación brasileña. Universidades, Ciudad de México, v. 71, n. 85, p. 11-32, 2020. Disponível em: http://udualerreu.org/index.php/universidades/article/view/274. Acesso em: 20 out. 2020.

PALUMBO, Dennis James. Public policy in America: government in action. 2. ed. Florida, EUA: Harcourt Brace \& Company, 1994. 
PAULA, Camila Henriques; ALMEIDA, Fernanda Maria. O programa Reuni e o desempenho das Ifes brasileiras. Ensaio: aval. pol. públ. Educ., Rio de Janeiro, v. 28, n. 109, p. 10541075, dez. 2020. Disponível em:

http://www.scielo.br/scielo.php?script=sci arttext\&pid=S010440362020000401054\&lng=en\&nrm=iso. Acesso em: $10 \mathrm{dez} 2020$.

TREVISOL, Joviles Vitório; BASTIANI, Sherlon Cristina; BRASIL, André. As dinâmicas da Pós-graduação em Santa Catarina: evolução e perspectivas (1969 - 2018). Avaliação, Campinas; Sorocaba, v. 25, n. 1, p. 178-198, abr. 2020. Disponível em: http://www.scielo.br/scielo.php?script=sci_arttext\&pid=S141440772020000100178\&lng=en\&nrm=iso. Acesso em: 20 out 2020.

TRINDADE PRESTES, Emília Maria; JEZINE, Edineide; SCOCUGLIA, Afonso Celso. Democratização do ensino superior brasileiro: o caso da Universidade Federal da Paraíba. Revista Lusófona de Educação, Lisboa, 2012. Disponível em: https://www.redalyc.org/articulo.oa?id=34924585011. Acesso em: 31 out. 2020.

UFMS. Plano de Desenvolvimento Institucional: PDI - 2010-2014. Campo Grande: Ed. UFMS, 2010. Disponível em: https://www.ufms.br/universidade/documentosoficiais/planode-desenvolvimento-institucional/. Acesso em: 25 out. 2019.

UFMS. Conselho Diretor. Resolução n. 45, de 10 de maio de 2016. Regulamento do Concurso Público para Ingresso na Carreira do Magistério Superior da Fundação Universidade Federal de Mato Grosso do Sul. Boletim de Serviço, Campo Grande, n. 6289, p. 6 de 13 de maio de 2016. Disponível em:

https://boletimoficial.ufms.br/bse/boletim?numero=6289. Acesso em: 31 out. 2019.

UFMS. Conselho Diretor. Resolução n. 62, de 28 de maio de 2018. Regulamenta Concurso Público para Ingresso na Carreira do Magistério Superior no âmbito da UFMS. Boletim de Serviço, Campo Grande, n. 6802, p. 10, 30 de maio de 2018. Disponível em: https://diorc.ufms.br/resolucao-no-622018-2/. Acesso em: 31 out. 2019.

UFGD. Plano de Desenvolvimento Institucional: PDI - 2013-2020. Dourados: Ed. UFGD, 2013. Disponível em:

http://files.ufgd.edu.br/arquivos/arquivos/78/ADMINISTRACAOUFGD/PDI\%20Prorrogado. pdf. Acesso em: 25 out. 2019. 